\title{
A afetividade do agente comunitário de saúde no território: um estudo com os mapas afetivos
}

\author{
The affection of the community healthcare agent in the territory: \\ a study with affective maps
}

Yandra Raquel do Nascimento Bezerra ${ }^{1}$

Maria Zelfa de Souza Feitosa ${ }^{2}$

${ }^{1}$ Escola de Saúde Pública do Ceará. Av. Antônio Justa 3161, Meireles. 60165090 Fortaleza CE Brasil. yandraraquel@ yahoo.com.br

${ }^{2}$ Universidade Federal do

Ceará. Fortaleza CE Brasil.
Abstract The community healthcare agent is an essential professional in the context of primary healthcare, helping to monitor the health of families in the territory. The scope of this study was to analyze the implications of affection on the performance of the community healthcare agent in the territory. The theoretical notions of this study are based on social psychology of a historical-cultural basis and environmental psychology. The survey was conducted with ten community healthcare agents at a basic health unit in a municipality of the State of Ceará. It is qualitative research, the data collection for which was carried out by applying the qualitative part of the Affective Map Generator Tool (IGMA). The data were analyzed using category content analysis and subtext, significance and motive analysis. The results revealed that the possibility of meeting each other and the bond built with families becomes a motivating force for the action of the community healthcare agents, giving rise to a positive engagement with the territory, despite the difficult context. We trust that this research will contribute to define new perspectives for the role of the community healthcare agent in the context of primary healthcare policy.

Key words Community healthcare agent, Affection, Affective map, Esteem for location
Resumo $O$ agente comunitário de saúde é um profissional essencial no contexto da Atenção Básica à Saúde, atuando no acompanhamento das famílias no território. O objetivo deste estudo foi analisar as implicações da afetividade na atuação do agente comunitário de saúde no território. As noções teóricas deste estudo estão baseadas na Psicologia Social de base histórico-cultural e na Psicologia Ambiental. A pesquisa foi realizada com dez agentes comunitários de saúde de uma Unidade Básica de Saúde em um município cearense. Trata-se de uma pesquisa qualitativa, cuja coleta de dados foi realizada por meio da aplicação da parte qualitativa do Instrumento Gerador dos Mapas Afetivos (IGMA). Os dados foram analisados por meio da Análise de Conteúdo Categorial e da Análise do subtexto, do sentido e do motivo. Os resultados obtidos revelaram que a possibilidade do encontro com o outro e do vínculo construído com as famílias se torna potencializador da ação dos agentes comunitários de saúde, fazendo emergir uma implicação positiva com o território, mesmo diante do contexto de dificuldades. Esperamos que esta pesquisa contribua para delinear novas perspectivas a respeito da atuação do agente comunitário de saúde no contexto da política de Atenção Básica à Saúde.

Palavras-chave Agente Comunitário de Saúde, Afetividade, Mapa afetivo, Estima de lugar 


\section{Introdução}

A Política Nacional de Atenção Básica (PNAB) foi instituída no País com o objetivo de desenvolver uma atenção integral à saúde da população, de acordo com os princípios e diretrizes do Sistema Único de Saúde (SUS), para garantir a acessibilidade, integralidade da assistência, autonomia, corresponsabilização, participação social, acolhimento e vinculação dos usuários com os serviços de saúde. A Atenção Básica se efetiva nas ações da Estratégia Saúde da Família (ESF), sob a forma do trabalho das equipes de saúde multiprofissionais, que assumem a responsabilidade sanitária pela população de um determinado território, considerando a dinamicidade de vida e as necessidades de saúde das pessoas que vivem nesse território ${ }^{1}$.

Nesse contexto, surge a figura do Agente Comunitário de Saúde (ACS), profissional que compõe a equipe multiprofissional da ESF e tem uma atuação junto às famílias do território adscrito das Unidades Básicas de Saúde (UBS). Esse território de atuação do ACS deve ser compreendido como um processo vivo, dinâmico, um espaço de vida dos sujeitos, onde se estabelecem as relações sociais e ocorre a produção do cuidado em saú$\mathrm{de}^{2}$. O ACS é um elo fundamental na articulação das ações da ESF, fortalecendo as relações e favorecendo a comunicação entre a comunidade e os profissionais de saúde, por residir no território e conhecer de perto a realidade de vida da população ${ }^{3}$.

Esse estudo analisa a dimensão afetiva do ACS no território, investigando os afetos do ACS, que emergem da inserção comunitária e das vivências cotidianas. Afetividade aqui é compreendida como tudo o que afeta o sujeito, aumentando ou diminuindo sua potência de ação ${ }^{4}$. O estudo dessa temática se torna relevante, visto que no campo da saúde a atenção geralmente se volta para os aspectos cognitivos, racionais e pouco se enfatiza o afeto, que está na base da razão e constitui as inter-relações humanas, sociais e ambientais, ainda que se admita que não é possível separar o sujeito de seus afetos.

Estudar a afetividade dos ACS no território se justifica pela necessidade de olhar para esse sujeito em sua integralidade, reconhecer as dimensões psicossociais desse profissional, que emergem na inter-relação pessoa-ambiente, entendendo esse ambiente como sociofísico, e conhecer o quanto esses afetos potencializam ou despotencializam a sua ação, podendo levar os ACS a se implicarem de maneira positiva ou negativa no desenvolvimento de sua atuação na comunidade.
O interesse por esse tema surgiu a partir da experiência de uma das autoras, como residente em uma UBS de um município do Ceará, onde foi possível conhecer o trabalho do ACS e partilhar sua vivência no território, por meio das ações de saúde multiprofissionais. Dessa forma, percebemos que esse profissional é uma figura importante no território, assumindo o papel de referência das ações de saúde na comunidade, e que, portanto, necessita ser compreendido em sua totalidade.

A afetividade é a categoria de análise nesse estudo, sendo entendida a partir das concepções da Psicologia Social de base histórico-cultural. Segundo Sawaia ${ }^{4,5}$ e Bomfim ${ }^{6}$, as quais se pautam nas formulações de Espinosa acerca da afetividade, a afetividade é uma categoria síntese, que permite romper com as dicotomias corpo e mente, objetivo e subjetivo, indivíduo e sociedade, entre outras. Em uma compreensão dialética da realidade, corpo e mente, afeto e razão constituem uma mesma coisa, fazem parte da integralidade da realidade e não podem ser dissociados. Em suas ações, o sujeito age integralmente com seu corpo e sua mente, sua cognição e emoção, subjetiva e objetivamente.

$\mathrm{Na}$ filosofia de Baruch de Espinosa, assim como na Psicologia Social, a afetividade é entendida como ética e política, que norteia as ações humanas ${ }^{5}$. Espinosa desenvolveu uma teoria dos afetos que busca a superação da servidão em busca da liberdade e autonomia do ser humano. Nesta compreensão, afetações que promovem a alegria aumentam a capacidade de existir, e, portanto, potencializam a ação humana, enquanto as paixões tristes diminuem essa capacidade de agir, reduzindo sua potência de ação ${ }^{5}$.

A Psicologia Ambiental estuda a inter-relação pessoa-ambiente ${ }^{6}$, considerando os vínculos cognitivos e afetivos que emergem dessa interação do sujeito com o ambiente, e nesse processo o indivíduo tem o poder de transformar e ser transformado. Esses conceitos são importantes para a compreensão da interação do ACS com o território, visto que é um profissional que está imerso na comunidade, compartilhando as vivências e desenvolvendo as ações de saúde em um ambiente sociofísico.

Compreendemos que o profissional ACS está inserido no contexto comunitário e partilha das vivências cotidianas nesse espaço de vida e trabalho. A interação com o lugar é permeada pela presença de afetos $^{7}$ e essa afetividade pode promover ação ou passividade ${ }^{5}$, a partir da capacidade do sujeito de afetar e ser afetado no contex- 
to das inter-relações. Diante disto, temos como pergunta de partida de nosso trabalho: Quais implicações os afetos, sejam potencializadores ou despotencializadores, que emergem da interação comunitária e da atuação no território, trazem à atuação do ACS?

Diante das questões apresentadas acerca do trabalho do ACS e da necessidade de compreensão da dimensão subjetiva desse profissional, tomamos como nosso objetivo analisar as implicações da afetividade na atuação do agente comunitário de saúde no território.

Esperamos que essa pesquisa possa delinear novas perspectivas a respeito da atuação do ACS no contexto da Atenção Básica, considerando os sentimentos, emoções e sentidos que emergem nessa interação do ACS com o território.

\section{Metodologia}

\section{Instrumento de coleta de dados e procedimentos de análise}

Nossa pesquisa caracteriza-se como uma investigação de cunho qualitativo, em que foi utilizada, para a coleta dos dados, a metodologia do Instrumento Gerador dos Mapas Afetivos (IGMA). Este instrumento, desenvolvido por Bomfim $^{6}$ em sua tese de Doutorado, possibilita a apreensão dos afetos em relação ao ambiente, que podem ser expressos através da linguagem, imagens, metáforas, sentimentos e emoções do individuo, e baseia-se nas concepções teóricas da Psicologia Social e Ambiental de base psicossocial e histórico-cultural ${ }^{6}$.

O IGMA permite investigar a Estima de Lugar $^{6}$, uma categoria ambiental, construída na relação social, que nos diz sobre a implicação do sujeito com o lugar e de sua ação no mesmo ${ }^{6}$. A qualificação da Estima é dada a partir das imagens geradas pelo IGMA, que são: 1) agradabilidade, que diz respeito ao quanto o sujeito avalia o ambiente como agradável, atrativo, capaz de suprir suas necessidades; 2) pertencimento, que se relaciona ao quanto o sujeito sente-se apropriado, considerando o lugar como algo seu, ainda que não tenha uma posse legal do mesmo. Estas duas primeiras categorias remetem a uma Estima de Lugar potencializadora, na qual o sujeito sente-se implicado com o lugar, participa dele, defende-o.

As outras categorias são: 3 ) insegurança, onde emergem sentimentos de incerteza e instabilidade em relação ao ambiente; e 4) destruição, que sur- ge nos sentimentos e qualidades despotencializadoras em relação às características físicas do espaço. Por gerarem sentimentos que levam o sujeito à passividade, amedrontam-no e entristecem-no, estas duas últimas categorias qualificam a Estima como despotencializadora. Por último, a imagem de 5) contrastes, denota os sentimentos ambíguos em relação ao ambiente, compondo-se de polarizações, e pode tanto expressar uma Estima de Lugar potencializadora como Despotencializadora, dependendo dos sentimentos, qualidades e afetos que são apresentados pelos sujeitos ${ }^{8}$.

O IGMA compõe-se originalmente dos seguintes itens, conforme Bomfim ${ }^{6}$ : Desenho, Significado do desenho, Sentimentos, Palavras-sínteses, $\mathrm{O}$ que pensa da cidade, Categorias da Escala Likert, Caminhos percorridos, Participação em Associação, Participação em movimentos sociais e Características demográficas.

O desenho é o primeiro item do instrumento e tem o objetivo de facilitar a expressão de sentimentos e emoções sobre o ambiente em estudo. Em seguida é solicitado ao sujeito para esclarecer a estrutura e o significado do próprio desenho. Depois o sujeito é convidado a descrever os sentimentos a respeito do desenho. Posteriormente, o sujeito é solicitado a citar seis palavras que expressem os sentimentos, qualidades ou substantivos atribuídos ao desenho. No próximo item, o sujeito tem a oportunidade de descrever o que pensa do ambiente. No item seguinte, é solicitado ao sujeito para comparar o ambiente com algo, e, logo depois, descrever os caminhos percorridos com maior frequência nesse ambiente. Os próximos itens buscam conhecer a participação dos sujeitos em associações e movimentos sociais no ambiente em estudo. E o último item contempla as características demográficas como: idade, sexo, renda, escolaridade, tempo de residência na cidade e outros. A Escala de tipo Likert, que compõe a parte quantitativa do instrumento, não foi utilizada na pesquisa.

Em nossa pesquisa foram necessárias adaptações no instrumento inicial para adequar ao contexto da pesquisa. O termo "microárea" foi escolhido para designar o território de atuação do profissional ACS. Dessa forma, foi utilizado da proposta inicial o desenho, o significado do desenho, os sentimentos, as palavras-sínteses, o que pensa de sua microárea de atuação, a comparação da microárea de atuação com algo, caminhos percorridos e participação em movimentos sociais. Os outros itens foram adaptados para: potencialidades na microárea e principais dificuldades na microárea. 
Para a análise dessa pesquisa foi utilizada uma adaptação do modelo de quadro síntese para categorização dos dados, a partir da proposta original de Bomfim ${ }^{6}$, conforme o modelo apresentado no Quadro 1.

O trabalho foi aprovado no Comitê de Ética em Pesquisa (CEP) da Escola de Saúde pública do Ceará (ESP), no dia 03 de setembro de 2015, de acordo com a Resolução 466/12, do Conselho Nacional de Saúde.

\section{Cenário da pesquisa e participantes}

A pesquisa foi realizada em uma Unidade Básica de Saúde (UBS), no município de Quixadá, localizado na Região do Sertão Central Cearense. A UBS fica localizada na área urbana e atende a população de um extenso território demográfico, compreendido por cinco (05) bairros urbanos e três (03) comunidades da área rural. A UBS conta com duas (02) Equipes de profissionais da ESF e um total de 18 profissionais ACS responsáveis por uma determinada microárea. Cada território é demarcado pelas características próprias de cada comunidade e sua população com seus aspectos sociais, culturais, econômicos e epidemiológicos, e essa realidade precisa ser considerada na realização das ações de saúde.

Participaram da pesquisa 10 ACS que atuam na referida Unidade de Saúde. Os ACS foram convidados para participar da pesquisa através de informes na Unidade de Saúde e contato por telefone, realizado pela pesquisadora. A proposta inicial era aplicar o IGMA com todos os 18 ACS da UBS, mas no dia previsto para coleta dos dados compareceram 10 ACS, pois alguns estavam de férias e outros de licença-saúde. Este fato não gerou prejuízos para a pesquisa, uma vez que, segundo o critério do ponto de saturação adotado, consideramos os dados suficientemente coletados quando, nas análises, as categorias dos Mapas Afetivos, que são apresentadas posteriormente, começam a se repetir, o que foi contemplado em nosso estudo.

Antes de aplicar o instrumento, os ACS foram informados sobre os objetivos da pesquisa e dos aspectos éticos do estudo, mediante a disponibilização do Termo de Consentimento Livre e Esclarecido (TCLE). A aplicação do IGMA teve duração entre 20 a 30 minutos, 02 instrumentos foram aplicados individualmente e os outros 08 instrumentos em pequenos grupos, com as devidas orientações, esclarecimentos de dúvidas e suporte da pesquisadora.

Os sujeitos participantes da pesquisa, quanto ao sexo, em sua maioria foram do sexo feminino, visto que do total de 10 sujeitos, foram 09 mulheres e 01 homem. A idade dos sujeitos variou de 28 a 56 anos, sendo que a maior parte (06 sujeitos) se encontra na faixa etária entre 28 e 36 anos de idade. Outra questão identificada na pesquisa foi o tempo de atuação na profissão de ACS, a maioria dos sujeitos respondeu até 02 anos de profissão (09 sujeitos) e, apenas 01 sujeito, apresentou 07 anos de profissão.

\section{Resultados e discussão}

A análise do conjunto geral das questões do IGMA possibilitou a construção das imagens dos Mapas Afetivos dos ACS em relação à microárea

Quadro 1. Síntese do processo de categorização direcionado à elaboração dos mapas afetivos.

\begin{tabular}{|l|l|}
\hline \multirow{2}{*}{ Identificação } & $\begin{array}{l}\text { Sujeito no: } \\
\text { Tempo de atuação como ACS: } \\
\text { Área_ }\end{array}$ \\
\hline Estrutura & $\begin{array}{l}{ }^{*} \text { Mapa cognitivo de Lynch: desenho de aspectos físicos do território de atuação, tais como } \\
\text { monumentos, construções, caminhos, limites, etc. } \\
{ }^{*} \text { Metafórico: desenho que expressa, por analogia, o sentimento ou o estado de ânimo do } \\
\text { participante. }\end{array}$ \\
\hline Significado & Explicação do participante sobre o desenho. \\
\hline Qualidade & Atributos do desenho e do serviço, apontados pelo participante. \\
\hline Sentimento & Expressão afetiva do participante ao desenho e da microárea de atuação. \\
\hline Metáfora & $\begin{array}{l}\text { Comparação da microárea de atuação com algo, pelo participante, que tem como função a } \\
\text { elaboração de metáforas. }\end{array}$ \\
\hline Sentido & $\begin{array}{l}\text { Interpretação dada pelo investigador à articulação de sentidos entre as metáforas microárea } \\
\text { de atuação e as outras dimensões atribuídas pelo participante (qualidade e sentimentos). }\end{array}$ \\
\hline
\end{tabular}

Fonte: Adaptado de Bomfim ${ }^{6}$. 
de atuação, a partir dos sentimentos e qualidades atribuídos pelos sujeitos aos desenhos.

O desenho e o significado permitem classificar a estrutura do mapa em cognitivo ou metafórico. O desenho cognitivo remete a elementos mais estruturais e aspectos físicos do ambiente, enquanto que o desenho metafórico diz respeito aos aspectos mais subjetivos, afetivos e expressões de sentimentos ${ }^{6}$. Dos 10 mapas analisados, $08 \mathrm{se}$ apresentaram como metafóricos e 02 cognitivos. Percebe-se que os sujeitos participantes realizaram desenhos subjetivos expressando sentimentos, emoções e afetos do território de atuação e da convivência comunitária.

As imagens da microárea de atuação dos ACS, levantadas a partir da análise dos mapas, foram: contrastes, agradabilidade, e destruição. Não foram identificadas as imagens de pertencimento e insegurança. No Quadro 2 estão sintetizadas as imagens com as qualidades e sentimentos expressos pelos ACS nos mapas afetivos.

As imagens de contrastes foram encontradas em 06 mapas afetivos, mas esses contrastes estão relacionados com uma implicação positiva com o território. Não foram encontradas imagens de contrastes com implicação negativa. A estima potencializadora foi encontrada nas imagens de agradabilidade presente em três mapas afetivos, que revelaram os aspectos positivos e o vínculo do ACS com o território. Também surgiu em apenas um mapa a imagem de destruição que remete a uma estima despotencializadora da ação do ACS.
Durante a discussão dos resultados serão apresentados os quadros com um mapa afetivo referente a cada uma das imagens da microárea, levantadas pelos ACS a partir das questões do IGMA. A exposição desses mapas tem o objetivo de exemplificar a consolidação dos resultados e a construção do mapa afetivo para facilitar a compreensão do leitor acerca da análise dos dados.

\section{Imagens de contrastes: a implicação positiva do ACS em um território de contradições}

Nas imagens de contrastes encontradas nos mapas afetivos, os ACS se referiram às dificuldades vivenciadas no cotidiano do trabalho, como a falta de acesso às famílias e as precárias condições de infraestrutura do território, mas ao mesmo tempo também expressaram sentimentos de amor, amizade e vínculo em relação às famílias, sentindo-se útil em poder acompanhar o cuidado em saúde das pessoas da comunidade.

A afetividade, na noção da filosofia de Espinosa, é entendida como mediadora da açãotransformadora ${ }^{5}$, onde o corpo tem o poder de afetar e ser afetado por outros corpos, possibilitando bons ou maus encontros que podem aumentar ou diminuir a sua potência de ação. Bomfim ${ }^{6}$ considera que dos bons encontros derivam a implicação positiva com o lugar e aumenta a potência de ação do indivíduo. Percebe-se que a possibilidade do encontro com o outro e do

Quadro 2. Imagens da microárea de atuação, conforme as qualidades e sentimentos expressos pelos sujeitos respondentes.

\begin{tabular}{|l|l|l|}
\hline \multicolumn{1}{|c|}{ Imagem } & \multicolumn{1}{|c|}{ Qualidades } & \multicolumn{1}{c|}{ Sentimentos } \\
\hline Contrastes & $\begin{array}{l}\text { Pessoas educadas/ outras pessoas não; } \\
\text { Área que gosto de trabalhar/Trabalho deixa a } \\
\text { desejar, por não concluir as visitas; } \\
\text { Uma área em desenvolvimento/ Falta de } \\
\text { saneamento e outras providências para melhoria; } \\
\text { Microárea boa para trabalhar/Microárea com } \\
\text { algumas dificuldades. } \\
\text { Calmo/movimentado }\end{array}$ & $\begin{array}{l}\text { Impotência/Confiança; } \\
\text { Disponibilidade/Insatisfação; } \\
\text { Angústia/Vínculo; } \\
\text { Falta de esperança/ Acreditar mais } \\
\text { no sistema; } \\
\text { Alegrias/ Receios; } \\
\text { Tristeza/Responsabilização }\end{array}$ \\
\hline Agradabilidade & $\begin{array}{l}\text { Receptividade da maioria das famílias; Microárea } \\
\text { boa para trabalhar; Pessoas respeitosas; } \\
\text { Comunidade que busca ajudar o próximo }\end{array}$ & $\begin{array}{l}\text { Utilidade, satisfação, empatia, } \\
\text { interesse, atitude, esperança, } \\
\text { alegria, tranquilidade, amizade, } \\
\text { respeito, responsabilidade, } \\
\text { confiança, parceria, gratidão. }\end{array}$ \\
\hline Destruição & $\begin{array}{l}\text { Carência das famílias; Necessidade; Área que } \\
\text { precisa de ajustes; Esgoto a céu aberto e buracos; } \\
\text { Difícil de trabalhar. }\end{array}$ & $\begin{array}{l}\text { Tristeza. } \\
\text { Frustração. }\end{array}$ \\
\hline
\end{tabular}

Fonte: Elaborado pelas autoras. 
vínculo construído com as famílias se torna potencializador da ação dos ACS, fazendo emergir uma implicação positiva com o território, mesmo diante desse contexto de dificuldades.

A imagem de contraste foi observada no Mapa afetivo 06 (Quadro 3), onde o respondente compara a microárea com uma moeda, se referindo as diferentes realidades encontradas na microárea.

Nesse mapa, o sujeito enfatizou a dificuldade de acesso a todas as famílias, pois tem muitas casas onde não consegue realizar a visita domiciliar, fazendo emergir os sentimentos de tristeza, angústia e frustração que estão associados a uma estima despontecializadora da ação. Mas também expressa sentimentos de confiança e vínculo construído com as famílias que tem contato, que remetem a uma implicação positiva e contribuem para aumentar a potência de ação.

A falta de acesso às famílias foi recorrente nos mapas afetivos de outros ACS, onde os mesmos relataram a dificuldade de realizar as visitas domiciliares por encontrarem as casas fechadas. $\mathrm{E}$ essa questão pode estar relacionada com as relações de poder estabelecidas no contexto da saúde, onde prevalece o modelo biomédico de atenção à saúde. Merhy ${ }^{9}$, comentando sobre o processo de trabalho em saúde, afirma que o modelo assistencial de saúde opera na lógica do modelo médico hegemônico, que não considera a dimensão cuidadora e complementar dos outros saberes.

O ACS é um profissional que atua no âmbito da promoção e prevenção da saúde e não corresponde a esse modelo de atenção presente na sociedade, pois seu trabalho consiste no acompanhamento contínuo das famílias, realizando ações educativas, orientações sobre os cuidados em saúde entre outras atividades ${ }^{1}$.

A dificuldade para atender todas as famílias pela falta de acesso a algumas residências faz emergir uma estima despotencializadora da ação dos profissionais ACS, que expressaram tristeza e angústia por não concluir seu trabalho. Estes dados apresentam relação com a pesquisa acerca da identidade do ACS, na qual os autores perceberam que esses profissionais reconhecem as limitações da sua práxis, quando são colocados diante de situações difíceis da realidade, fazendo emergir sentimentos de impotência e limitação ${ }^{10}$.

Outra questão a ser considerada é a inserção do ACS na comunidade, Marzari et a $1 .{ }^{11}$, em sua pesquisa acerca do perfil e formação dos ACS, comentam que a inserção comunitária é um processo de construção permanente, pois, mesmo o agente de saúde sendo um morador, precisa estabelecer uma relação profissional e um envolvimento para compreender as demandas e necessidades da comunidade. Os autores lembram que essa adaptação pode ser lenta e o ACS necessita estar preparado para desenvolver essa atuação. Na pesquisa verificamos que a maioria dos ACS participantes tem pouco tempo de atuação na profissão, em torno de dois (02) anos. Entendemos que essa inserção comunitária está em processo de construção, na medida em que o trabalho é desenvolvido junto à população, e essa questão pode estar relacionada com as imagens de contrastes que emergiram nos mapas afetivos.

A falta de credibilidade dos usuários no sistema de saúde e no trabalho do profissional ACS foi outro ponto que emergiu nos mapas afetivos. Entendemos que o ACS está em contato direto

Quadro 3. Mapa afetivo 06.

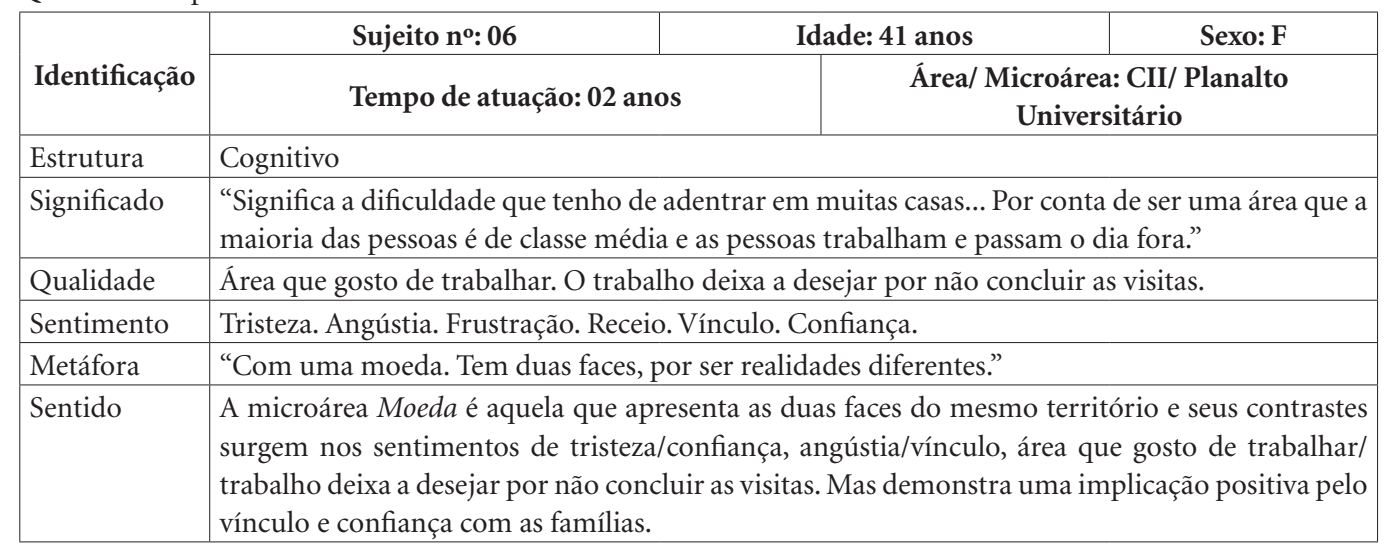

Fonte: Elaborado pelas autoras. 
com a população, conhece a realidade local e os problemas cotidianos das famílias, e nesses encontros e diálogos as pessoas encontram espaços para expor suas queixas e reclamações a respeito dos serviços de saúde vigente.

Soratto et al. ${ }^{12}$, em um estudo acerca da participação popular e controle social na ESF, relatam que a sociedade na maioria das vezes assume uma postura crítica a respeito da organização dos serviços de saúde e, em seus discursos, expressam queixas e reclamações desses serviços, mas não se efetiva em uma participação coletiva em prol de mudanças. As autoras ${ }^{11}$ ainda comentam que há dificuldade dos profissionais de saúde para mobilizar e incentivar processos de participação popular nos serviços de saúde, em vista do modelo centrado nas práticas de saúde hegemônicas.

Nessa perspectiva, o ACS deve reconhecer o seu papel de mediador entre a comunidade es serviços de saúde, acolher as demandas da população e assumir a postura ético-política de compromisso social para mobilizar a participação popular no SUS. O respondente expressa sentimentos potencializadores de solidariedade, atenção, afeto, considerando a microárea boa para trabalhar, que revelam uma implicação positiva com o território e envolvimento comunitário.

\section{Imagem de destruição: a microárea Deserto}

A imagem de destruição foi identificada apenas no mapa afetivo 03 (Quadro 4), onde o sujeito expressa a falta de infraestrutura do lugar, com esgotos, lixos e buracos que dificultam o trabalho, bem como a situação de vulnerabilidade das famílias, devido às condições de pobreza:
Esse cenário de deserto, dificuldade, vazio, abandono, pobreza, revelam uma estima despotencializadora, que faz emergir uma condição de sofrimento e despotencialização do ACS diante dos problemas presentes no território.

Sawaia ${ }^{5}$ define a noção de sofrimento ético -político, a partir da dialética inclusão/exclusão social, que tanto pode levar o sujeito a uma potência de ação ou a uma potência de padecimento diante das situações de opressão, desigualdade e exclusão social. Para a autora, é possível o enfrentamento e superação desse sofrimento psicossocial, transformando-o em possibilidade de ação ${ }^{4}$.

O profissional ACS, na sua atuação comunitária, é colocado diante das situações de vulnerabilidade e risco social, que podem desencadear uma condição de sofrimento ético-político, que podem aumentar a sua capacidade de agir no sentido do compromisso social e da participação cidadã no território, ou se tornar passivo e indiferente a essas questões presentes na sua realidade comunitária.

Mesmo diante da dificuldade de acesso a algumas famílias na comunidade, para realizar as visitas domiciliares, o sujeito expressa sentimentos de amizade e compaixão com as famílias, e, no mapa afetivo, as famílias são colocadas como representação da microárea. Esses sentimentos podem impulsionar o indivíduo na busca de autonomia, transformação social, e contribuir para aumentar a sua potência de ação no território, além de nos levar a pensar que esses sentimentos potencializadores podem ser comparados a um oásis que emana no meio desse deserto e podem fazer florescer a esperança, a motivação e a busca pela melhoria das condições de saúde e de vida da população.

Quadro 4. Mapa afetivo 03.

\begin{tabular}{|l|l|l|l|}
\hline \multirow{2}{*}{ Identificação } & Sujeito: 03 & Idade: 29 anos & Sexo:F \\
\cline { 2 - 3 } & Tempo de atuação: 02 anos & Área/Microárea: C1/Carrascal II \\
\hline Estrutura & Metafórico & \\
\hline Significado & $\begin{array}{l}\text { "O desenho representa para mim a maneira de como eu vejo as famílias, o que representa } \\
\text { mais pra mim na área são as minhas famílias." }\end{array}$ \\
\hline Qualidade & $\begin{array}{l}\text { Carência das famílias. Necessidade. Área que precisa de ajustes. Esgoto a céu aberto. Buracos. } \\
\text { Difícil de se trabalhar. Não tem o que dizer das famílias, uma conversa resolve. }\end{array}$ \\
\hline Sentimento & Tristeza. Frustração. Compaixão. Amizade. \\
\hline Metáfora & $\begin{array}{l}\text { "Deserto, pelo fato das famílias ficarem mais com suas casas fechadas, ou melhor, dentro de } \\
\text { suas casas, muitas vezes dificultando a visita." }\end{array}$ \\
\hline Sentido & $\begin{array}{l}\text { A microárea Deserto é aquela em que a destruição aparece pela falta de infraestrutura, buracos, } \\
\text { esgotos a céu aberto, tornando difícil de trabalhar. Ao mesmo tempo em que a implicação } \\
\text { positiva com as famílias faz emergir sentimentos de compaixão, amizade e afeto. }\end{array}$ \\
\hline
\end{tabular}

Fonte: Elaborado pelas autoras. 


\section{Imagens de agradabilidade: a estima potencializadora do ACS}

$\mathrm{Na}$ análise dos mapas afetivos a imagem de agradabilidade foi identificada nos sentimentos de respeito, empatia, parceria, confiança e compromisso demonstrado pelos ACS, em relação ao seu trabalho e ao acompanhamento das famílias no território. $E$ esses sentimentos de vínculo e qualidades positivas do lugar definem uma estima potencializadora.

No mapa afetivo 04 (Quadro 5) a imagem de agradabilidade é definida nos sentimentos de amizade, alegria, respeito e gratidão, onde a respondente faz referência aos aspectos positivos do território e o vínculo construído com as famílias.

Apesar de reconhecer a existência de problemas cotidianos, os mesmos não são percebidos como obstáculos para a continuidade do trabalho, pois o vínculo com a comunidade, o respeito e consideração das famílias, são elementos potencializadores do trabalho do ACS. Silva et al. ${ }^{13}$, em sua pesquisa acerca da participação social do ACS, relata que o vínculo afetivo criado pelo o ACS fortalece o seu papel de mediador entre o serviço de saúde e a comunidade.

Nos mapas afetivos onde surgiu a imagem da agradabilidade os respondentes expressaram também o compromisso em ajudar e a prontidão para acolher as demandas da comunidade. Mesmo reconhecendo que existe a falta de acesso a algumas famílias, fato que aparece em outros mapas e foi discutido anteriormente, relatam a receptividade e a interação com a maioria das famílias. Esses sentimentos de satisfação, empatia, utilidade e esperança emergem da interação do ACS com as famílias, e indicam a estima potencializadora do ACS com o território.
A estima indica a potência de ação e a participação cidadã do individuo em relação ao seu ambiente, os bons encontros são decorrentes de afetos potencializadores que emergem na inter -relação sujeito-ambiente e possibilitam a participação, envolvimento e apropriação do espaço ${ }^{5}$. Entendemos que a relação afetiva e o vínculo do ACS com as famílias promovem a participação no trabalho e o envolvimento com a comunidade em prol da transformação social.

\section{Considerações finais}

A análise dos mapas afetivos dos ACS possibilitou a construção de imagens que revelam sentimentos e afetos que emergem do processo de inserção comunitária e das vivências com as famílias no território. Os resultados obtidos na pesquisa mostraram que mesmo em face às dificuldades e contrastes do território, foi encontrada uma implicação positiva do ACS que emerge do vínculo, acolhimento, respeito e do sentir-se responsável pelas famílias. O bom encontro com o outro aparece, portanto, como o grande potencializador da ação profissional e da vinculação com o território, capaz de promover uma implicação positiva com o trabalho e o território.

A questão da falta de acesso às famílias foi um ponto recorrente nos mapas afetivos, e nos leva a refletir sobre o lugar que o ACS ocupa na comunidade e o quanto seu trabalho é reconhecido e legitimado pela população. $\mathrm{O}$ modelo biomédico de atenção à saúde prevalece na sociedade, onde as pessoas buscam as práticas curativas e medicalizantes, e o ACS surge como um profissional que atua diretamente na prevenção e promoção da saúde, o que não se enquadra nesse perfil bio-

Quadro 5. Mapa afetivo 04.

\begin{tabular}{|c|c|c|c|}
\hline \multirow{2}{*}{ Identificação } & Sujeito no:04 & Idade: 43 anos & Sexo: $\mathrm{F}$ \\
\hline & Tempo de atuação:7 anos & \multicolumn{2}{|c|}{ Área/Microárea: C1/Carrascal I } \\
\hline Estrutura & \multicolumn{3}{|l|}{ Metafórico } \\
\hline Significado & \multicolumn{3}{|c|}{ "A amizade e conforto, na comunidade encontrei certas amizades sinceras para sempre." } \\
\hline Qualidade & \multicolumn{3}{|c|}{ Comunidade que busca ajudar o próximo, carente e respeitosa. } \\
\hline Sentimento & \multicolumn{3}{|c|}{ Amizade, conforto, gratidão, alegria, respeito, consideração } \\
\hline Metáfora & \multicolumn{3}{|c|}{$\begin{array}{l}\text { "Um interruptor de uma lâmpada, por que tem dias que os problemas são fáceis de resolver } \\
\text { e outros não." }\end{array}$} \\
\hline Sentido & \multicolumn{3}{|c|}{$\begin{array}{l}\text { A microárea Interruptor de lâmpada é aquela onde a imagem de agradabilidade aparece nos } \\
\text { sentimentos de amizade, conforto, gratidão e respeito encontrados na convivência comunitária. }\end{array}$} \\
\hline
\end{tabular}


médico. Além disso, o ACS não ocupa o lugar do saber do especialista, privilegiado socialmente.

Estes aspectos, dentro das relações de poder que se estabelecem no cenário social, impactam diretamente na legitimação que sua fala adquire ou não no território, nas permissões que são dadas ou negadas a este profissional, para que possa transitar em alguns espaços. Neste jogo de poderes e saberes, o ACS pode ser entristecido, tendo sua potência de ação diminuída, assim como os bons encontros podem ser cada vez mais raros. Olhar para estes aspectos permite-nos, inclusive, pensar estratégias capazes de romper com a lógica dominante e com o que está instituído, delineando novas possibilidades de potencializar o profissional em campo, de maneira que sua ação possa gerar alegria e romper com a servidão sua e das famílias com quem trabalha. É nesta dimensão que a afetividade se constitui como categoria ética e política, sendo a via pela qual podemos pensar a transformação social.

Vislumbramos a necessidade de fortalecer a relação entre o ACS e as famílias, no contexto da Atenção Básica à Saúde, no sentido de facilitar o acesso e o acompanhamento do território. Pois é na possibilidade do encontro com o outro e com o ambiente, do cuidado e da atenção, que os ACS vivenciam as relações de afetos que potencializam a sua ação e a motivação para realizar o trabalho.

Nessa perspectiva ressaltamos a importância dos afetos potencializadores do ACS como fator protetivo para si mesmo diante das diversas situações que vivenciam na atuação cotidiana no território. As afetações positivas que emergem nesse processo de interação comunitária e vínculos com as famílias contribuem para o fortalecimento do profissional ACS na busca de melhoria do seu trabalho e compromisso social com a comunidade.

Esperamos que o estudo da afetividade dos ACS no território contribua para ampliar o olhar sobre a dimensão subjetiva na atenção básica, que está presente em todas as relações humanas e não pode ser negada, e que os resultados encontrados nesse estudo possam servir para fortalecer o papel do ACS e reconhecer o seu potencial de ação no território.

Podemos considerar que a realização desse trabalho foi uma experiência desafiadora e intensa, permeada de bons encontros, afetos e emoções, e não se torna o fim, mas o começo de uma caminhada, no sentido da busca e da construção de novos conhecimentos.

\section{Colaboradores}

YRN Bezerra trabalhou na elaboração e aplicação da pesquisa, análise e interpretação dos resultados e na redação do artigo. MZS Feitosa trabalhou na elaboração da pesquisa, orientação e interpretação dos resultados e na revisão crítica do artigo. 


\section{Referências}

1. Brasil. Ministério da Saúde (MS). Política Nacional de Atenção Básica. Brasília: MS; 2012.

2. Silva AMR, Oliveira MSM, Nunes EFPA, Torres ZF. A unidade básica de saúde e seu território. In: Andrade SM, Soares DA, Cordoni Júnior L, organizadores. Bases da saúde coletiva. Londrina: UEL; 2001. p.145-160.

3. Gomes KO, Cotta RMM, Mitre SMI, Batista RS, Cherchiglia ML. O agente comunitário de saúde e a consolidação do Sistema Único de Saúde: reflexões contemporâneas. Physis [Internet]. 2010 Dez [acessado 2015 Jun 29]; 20(4):1143-1164. Disponível em: http://www.scielo.br/scielo.php?script=sci_arttext\&pi$\mathrm{d}=$ S0103-73312010000400005\&lng=pt. http://dx.doi. org/10.1590/S0103-73312010000400005.

4. Sawaia BB, organizador. As Artimanhas da Exclusão: análise psicossocial e ética da desigualdade social. $2^{\mathrm{a}} \mathrm{ed}$. Petrópolis: Vozes; 2001.

5. Sawaia BB. Psicologia e desigualdade social: uma reflexão sobre liberdade e transformação social. Psicologia \& Sociedade 2009; 21(3):364-372.

6. Bomfim ZAC. Cidade e Afetividade: Estima e construção dos mapas afetivos de Barcelona e de São Paulo. Fortaleza: Edições UFC; 2010.

7. Lima DMA, Bomfim ZAC. Vinculação afetiva pessoa -ambiente: diálogos na psicologia comunitária e psicologia ambiental. Psico 2009; 40(4):491-497.

8. Bomfim ZAC, Nobre B, Ferreira T, Araújo L, Feitosa M, Martins A, Alencar H, Farias N. Affective maps: validating a dialogue between qualitative and quantitative methods. In: Mira RG, Dumitru A, editors. Urban sustainability: Innovative spaces, vulnerabilities and opportunities. A Coruña: Deputación Provincial de A Coruña, Institute of Psych osocial Studies and Research "Xoan Vicente Viqueira"; 2014. p. 131-148.

9. Merhy EE. A perda da dimensão cuidadora na produção da saúde: uma discussão do modelo assistencial e da intervenção no seu modo de trabalhar a assistência. Campinas: DMPS/FCM/Unicamp; 1997.

10. Bachilli RG, Scavassa AJ, Spiri WC. A identidade do agente comunitário de saúde: uma abordagem fenomenológica. Cien Saude Colet [internet] $2008 \mathrm{Fev}$ [acessado 2015 Jun 20] 13(10):51-60. Disponível em: http://www.scielo.br/scielo.php?script=sci_arttext\&pi$\mathrm{d}=$ S1413-81232008000100010\&lng $=\mathrm{pt}$
11. Marzari CK, Junges JR, Selli L. Agentes Comunitários da saúde: perfil e formação. Cien Saude Colet [internet]2011[acessado 2015 Ago 10]; 16(Supl. 1):873-880. Disponível em: http://www.scielo. br /scielo.php?scrip$\mathrm{t}=$ sci_arttext\&pid=S1413-81232011000700019\&lng=e n\&nrm=iso $>$. http://dx.doi.org/10.1590/S1413-81232 011000700019

12. Soratto J, Witt RR, Faria EM. Participação popular e controle social em saúde: desafios da Estratégia Saúde da Família. Physis [Internet] 2010 Dez [acessado 2015 Ago 10]; 20(4):1227-1243. Disponível em: http:// www.scielo.br/scielo.php?script=sci_arttext\&pi$\mathrm{d}=$ S0103-73312010000400009\&lng $=\mathrm{pt}$

13. Silva CRC, Rosilda M, Ramiz CP, Anhas DM, Rosa KRM. Participação social e a potência do agente comunitário de saúde. Psicologia \& Sociedade [internet] 2014, [acessado 2015 Jun 20] 26 (1):113-123. Disponível em: http://www.scielo.br/scielo.php?script=sci_arttext\&pid=S0102-71822014000600012\&lng=en\&n$\mathrm{rm}=\mathrm{iso}$

Artigo apresentado em 06/01/2016

Aprovado em 14/06/2016

Versão final apresentada em 16/06/2016 